\title{
Optical clock recovery employing an optical PLL using cross-phase modulation in a Sagnac-interferometer
}

Oxenløwe, Leif Katsuo; Schubert, C.; Schmidt, C.; Hilliger, E.; Berger, J.; Feiste, U.; Ludwig, R.; Weber, H. G.

Published in:

Summaries of papers presented at the Technical Digest Conference on Lasers and Electro-Optics

Link to article, DOI:

10.1109/CLEO.2001.948126

Publication date:

2001

Document Version

Publisher's PDF, also known as Version of record

Link back to DTU Orbit

Citation (APA):

Oxenløwe, L. K., Schubert, C., Schmidt, C., Hilliger, E., Berger, J., Feiste, U., Ludwig, R., \& Weber, H. G. (2001). Optical clock recovery employing an optical PLL using cross-phase modulation in a Sagnacinterferometer. In Summaries of papers presented at the Technical Digest Conference on Lasers and ElectroOptics (pp. 525-526) https://doi.org/10.1109/CLEO.2001.948126

\section{General rights}

Copyright and moral rights for the publications made accessible in the public portal are retained by the authors and/or other copyright owners and it is a condition of accessing publications that users recognise and abide by the legal requirements associated with these rights.

- Users may download and print one copy of any publication from the public portal for the purpose of private study or research.

- You may not further distribute the material or use it for any profit-making activity or commercial gain

- You may freely distribute the URL identifying the publication in the public portal 


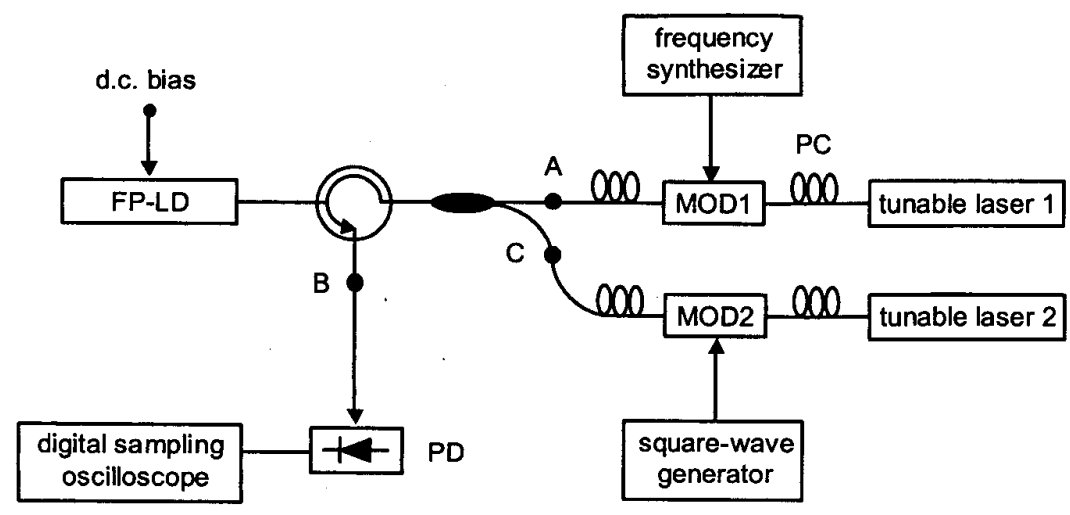

CThU1 Fig. 1. Experimental setup of the all-optical clock division.

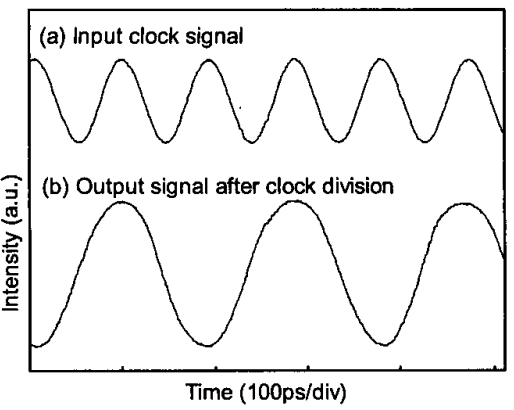

CThU1 Fig. 2. Sinusoidal signals showing (a) the input and (b) the output of the all-optical clock division scheme.

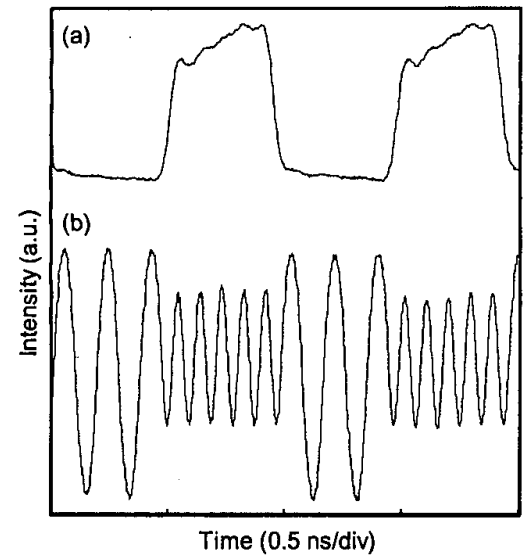

CThU1 Fig. 3. (a) The modulated waveform and (b) the corresponding optical clock output.

GaAsP semiconductor lasers," Appl. Phys. Lett., vol. 55, pp. 822-824, 1989.

4. H.F. Liu and W.F. Ngai, "Nonlinear dynamics of a directly modulated $1.55 \mathrm{~mm}$ InGaAsP distributed feedback semiconductor laser," IEEE J. Quantum Electron., vol. 29, pp. 1668$1675,1993$.
5. Y. Matsui, S. Kutsuzawa, S. Arahira, Y. Ogawa and A. Suzuki, "Bifurcation in 20-GHz Gainswitched 1.55-mm MQW lasers and its control by cw injection seeding," IEEE J. Quantum Electron., vol. 34, pp. 1213-1223, 1998.

\section{CThU2}

5:00 pm

Optical clock recovery employing an optical PLL using cross-phase modulation In a Sagnac-Interferometer

L.K. Oxenløwe, C. Schubert, ${ }^{*}$ C. Schmidt, ${ }^{*}$ E. Hilliger, ${ }^{*}$ J. Berger, ${ }^{*}$ U. Feiste, R. Ludwig, ${ }^{*}$ H.G. Weber, ${ }^{*}$ Research Center COM, Technical University of Denmark, Building 345V, DK-2800 Lyngby,Denmark; E-mail: lo@com.dtu.dk; ${ }^{*}$ Heinrich-Hertz-Institut für Nachrichtentechnik, Einsteinufer 37, D-10587 Berlin, Germany

Clock recovery $(\mathrm{CR})$ is an essential part of any transmission system. In this paper we propose a new type of optical clock recovery based on an optical PLL, where a SLALOM ${ }^{1}$ acts as ultrafast phase comparator.

The principle is seen in the experimental setup (Fig. 1). A data signal at $1550 \mathrm{~nm}$ with a high line bit-rate $\mathrm{f}_{\text {data }}$, $\mathrm{n}$-times time-division multiplexed from a $10 \mathrm{~Gb} / \mathrm{s}$ base-rate, enters the SLALOM. Optical pump pulses (pulse width 2 ps, wavelength $1540 \mathrm{~nm}$ ) from a tuneable modelocked semiconductor laser (TMLL), ${ }^{2}$ that is hybridly mode-locked by an electrical VCO, generate switching windows in the SLALOM at a repetition rate $f_{v c o}$ near the base-rate of the sig-
CThU2 Fig. 1. Schematic set-up. nal. If pump and data signal are not synchronized the switching window is scanned by the data pulses with the difference frequency. The principle of the PLL is to use the optical output of the SLALOM as an error signal, which locks the local VCO to the data base-rate.

In the experiments we used optical pulses from a second tuneable mode-locked laser at 10 $\mathrm{GHz}$ (pulse width $2 \mathrm{ps}$ ). The pulses were modulated with a $2^{7}-1$ PRBS sequence and passively multiplexed to generate a $40,80,160 \mathrm{~Gb} / \mathrm{s}$ PRBS data signal. We characterized the clock recovery circuit by measuring the single sideband phase noise (SSB) of the recovered optical clock pulses with an electrical RF spectrum analyser and by comparing it to the phase noise of the incoming data signal. Fig. 3a) shows the SSB phase noise for an incoming $40 \mathrm{GHz}$ pulse stream. A timing jitter of about $350 \mathrm{fs}$ can be derived from the phase noise curve. With the PLL loop open, we find a large phase noise of the clock pulses, Fig. $3 b)$. With the loop closed we obtain the same jitter as that of the incoming data signal, Fig. 3c).

Fig. 4 shows the recovered frequency spectra for the case of a 40,80 and $160 \mathrm{~Gb} / \mathrm{s}$ data signal. At 40 and $80 \mathrm{~Gb} / \mathrm{s}$, the jitter of the recovered clock was the same as that of the signal laser ( 610 and $620 \mathrm{fs}$ respectively). This value is somewhat higher than in the $40 \mathrm{GHz}$ case due to a different pulse source used, and a pedestal and some distinct sidebands are present, stemming from the data signal, showing that the PLL circuit is fast enough to follow these phase changes.

At $160 \mathrm{~Gb} / \mathrm{s}$ (Fig. 4c), the locking was not stable long enough to measure the phase noise, since the electrical feedback loop was not optimised for $160 \mathrm{~Gb} / \mathrm{s}$. This should be possible though, since the capture range at $160 \mathrm{~Gb} / \mathrm{s}$ is about $1.5 \mathrm{ps}$, and the signal jitter was less than 1 ps. Following the approach of, ${ }^{3}$ the results obtained here should be adequate to demultiplex error free at $80 \mathrm{~Gb} / \mathrm{s}$.

In conclusion, we propose a SLALOM as a fast phase comparator in an optical PLL based clock recovery scheme. The scheme has been demonstrated successfully at bit rates up to $160 \mathrm{~Gb} / \mathrm{s}$.

\section{References}

1. M. Eiselt et al., IEEE J. Lightwave Technol., Vol. 13, No. 10, 1995.

2. R. Ludwig et al., OECC'2000, Chiba, Japan 2000.

3. M. Jinno, IEEE J. Quantum Electron., Vol. 30, No. 12, 1994

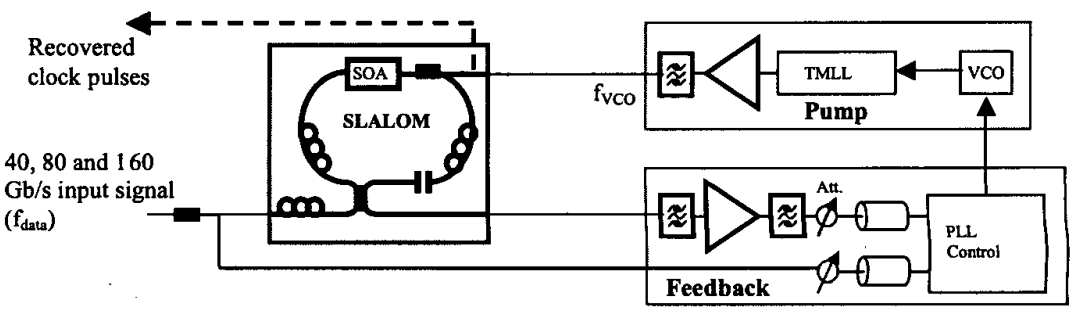



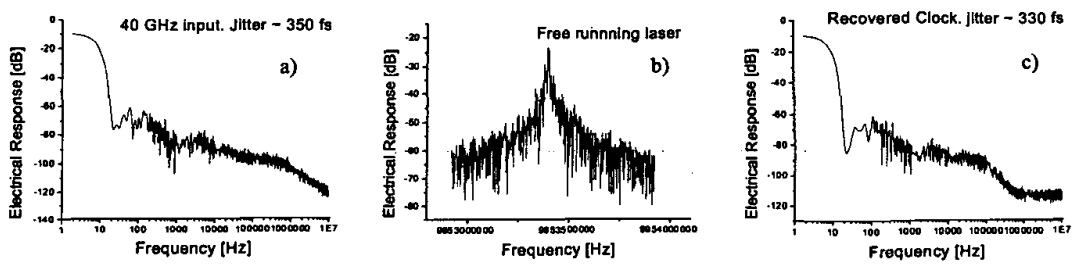

CThU2 Fig. 3. a) Single Sideband Phase Noise of $40 \mathrm{GHz}$ pulse stream, b) RF spectrum of free running clock pulses, c) Single Sideband Phase Noise of recovered clock pulses.
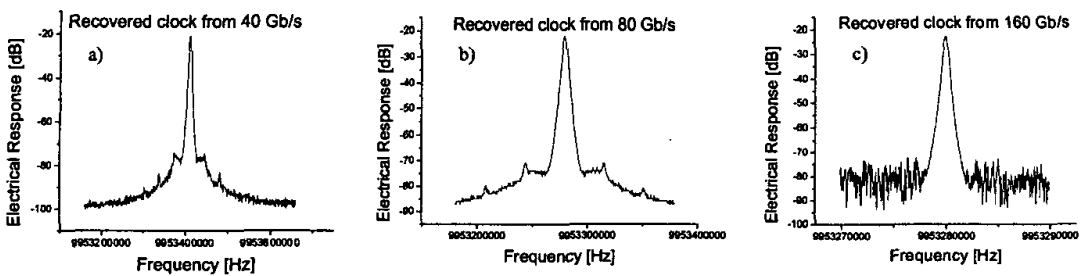

CThU2 Fig.4. RF spectra of recovered clock pulses from a a) $40 \mathrm{~Gb} / \mathrm{s}$ data signal, b) $80 \mathrm{~Gb} / \mathrm{s}$ data sig$\mathrm{nal}, \mathrm{c}) 160 \mathrm{~Gb} / \mathrm{s}$ data signal.

CThu3

Ultrahigh speed OTOM transmission systems and sub-systems

Hidehiko Takara, Kentaro Uchiyama, Ippei Shake, Toshio Morioka, NTT Network Innovation Laboratories, Hikari-no-oka, Yokosuka, Kanagawa, 239-0847 Japan; Email: takara@exa.onlab.ntt.co.jp

Ultra-high speed optical time-division-multiplexed (OTDM) transmission systems are becoming increasing important as one of the key technologies capable of satisfying the growing demand for large capacity optical networks. OTDM has several advantages in terms of system operation such as natural accommodation of higher bit rate payloads, and ease of supervising the multiplexed line. OTDM was proposed in 1988 in order to overcome the electrical TDM system speed limit, ${ }^{1}$ and since then its bit rate has been significantly increased to $1.28 \mathrm{Tbit} / \mathrm{s}$ as shown in Fig. 1..$^{2-4}$ From this figure, we see that the bit-rate is increasing at 40 times/ 10 years. This paper focuses on recent developments in OTDM transmission systems and sub-systems.

Main functions in the OTDM transmitter are

CThU3 Fig. 1. Bit rate in optical transmission experiments.

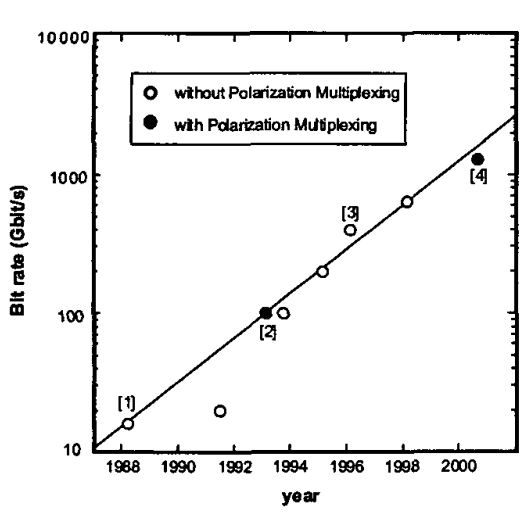

optical short pulse generation and multiplexing. For ultrahigh speed OTDM transmission, it is essential to generate short transform-limited (TL), low-jitter optical pulses that are synchronized to a master clock. We have developed a supercontinuum (SC) light source. ${ }^{5}$ By nonlinearly pumping optical fiber with picosecond optical pulses, spectral broadening greater than $200 \mathrm{~nm}$ is possible. Picosecond or femtosecond short TL optical pulses can be obtained by filtering the SC spectrum. Time-division-multiplexing of optical signals with stable pulse separation is important in order to suppress the influence of the crosstalk from adjacent pulses on demultiplexing, and to minimize the jitter in timing extraction. Integrating the optical elements into a small circuit is one solution to make pulse separation stable because of the shorter optical path lengths and simpler temperature control. An OTDM multiplexer, recently constructed on a hybrid integrated planar lightwave circuit, ${ }^{6}$ multiplexes four $20 \mathrm{Gbit} / \mathrm{s} \mathrm{op-}$ tical signals into an $80 \mathrm{Gbit} / \mathrm{s}$ signal. This device is expected to be applied to over-160 Gbit/s OTDM systems.

The OTDM receiver consists of several functions such as demultiplexing, clock recovery, and dispersion compensation. The requirements imposed on the demultiplexing function are ultrafast operation, polarization-independency, and multiple output operation. So far, several ultrafast demultiplexing experiments have been reported that were based on nonlinear effects such as four wave mixing and cross phase modulation (XPM). Multiple output demultiplexing with low polarization dependency has been successfully demonstrated by using MOXIC (Multiple-channel Output all-optical OTDM demultiplexer using XPM-induced Chirp Compensation). ${ }^{7}$ Ultralow-jitter clock recovery is also required, so many clock recovery methods have been proposed including injection locking and PLL. Bit-phase synchronization between the OTDM signal and the control pulses is an important for robust demultiplexing operation. Bit-phase synchronization methods based on photonic down-conversion have recently been demonstrated as shown in Fig. 2. This method achieved the control pulse timing jitter of $0.12 \mathrm{ps}$ and kept relative timing displacement to better than $0.7 \mathrm{ps}$.

OTDM signal waveform measurement is indispensable in evaluating high-speed OTDM systems. An ultra-fast waveform measurement system based on sum-frequency-generation optical sampling has been developed. ${ }^{8}$ This system can measure the eye-diagrams of over $160 \mathrm{Gbit} / \mathrm{s} \mathrm{op}$ tical signals. Signal quality monitoring is also essential for realizing OTDM systems. Asynchronous monitoring methods based on the optical sampling that enable Q-factor measurement of ultra-high speed OTDM signals without timing extraction ${ }^{9}$ have been investigated (see Fig. 3). Qfactors can be estimated from the amplitude histogram of the asynchronous measured eye-diagram. This system has been confirmed to offer $160 \mathrm{Gbit} / \mathrm{s}$ OTDM signal quality monitoring. ${ }^{9}$

We will also describe dispersion compensation and transmission, and briefly discuss the impact of optical nonlinear effects, such as inter-bit FWM, on OTDM transmission systems.

\section{References}

1. R.S. Tucker et al., Tech. Dig. OFC'88, Paper ThB2 (1988).

2. S. Kawanishi et al., Electron. Lett., 29, 1075 (1993).

3. S. Kawanishi et al., Electron. Lett., 32, 916 (1996).

4. M. Nakazawa et al., Tech. Dig. ECOC2000, Paper PD2.6 (2000).

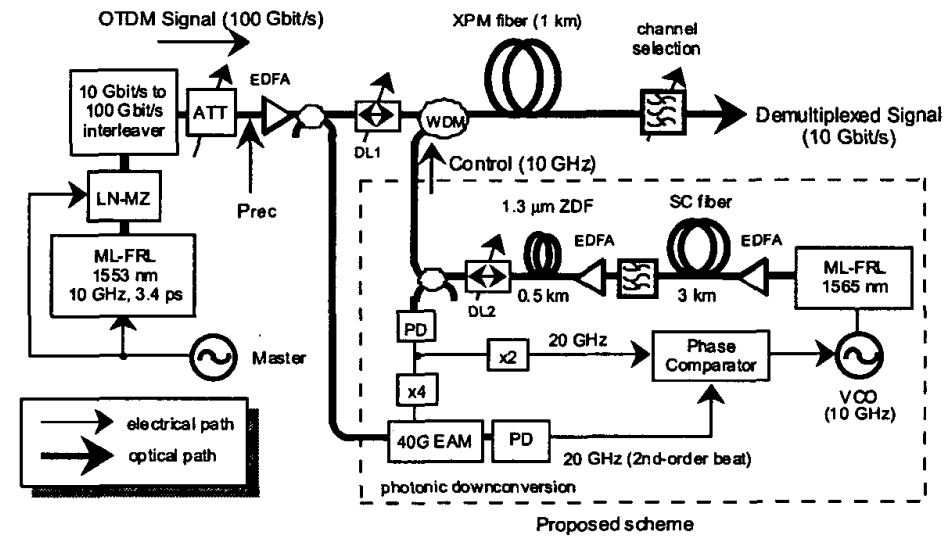

CThU3 Fig. 2. OTDM demultiplexer with bit-synchronization scheme. 